\title{
Endogenous generation of hydrogen sulfide and its regulation in Shewanella oneidensis
}

\section{OPEN ACCESS}

Edited by:

Dongsheng Zhou,

Beijing Institute of Microbiology and

Epidemiology, China

Reviewed by:

Atsushi Kouzuma,

Tokyo University of Pharmacy and Life

Sciences, Japan

Jürgen Lassak,

Ludwig-Maximilians-Universität

Munich, Germany

*Correspondence:

Haichun Gao,

Institute of Microbiology and College of Life Sciences, Zhejiang University,

Hangzhou, Zhejiang 310058, China haichung@zju.edu.cn

Specialty section:

This article was submitted to

Food Microbiology

a section of the journal

Frontiers in Microbiology

Received: 28 February 2015

Accepted: 12 April 2015

Published: 28 April 2015

Citation:

Wu G, Li N, Mao Y, Zhou G and Gao $H$ (2015) Endogenous generation of hydrogen sulfide and its regulation in

Shewanella oneidensis.

Front. Microbiol. 6:374.

doi: 10.3389/fmicb.2015.00374

\author{
Genfu Wu, Ning Li, Yinting Mao, Guangqi Zhou and Haichun Gao* \\ Institute of Microbiology and College of Life Sciences, Zhejiang University, Hangzhou, China
}

Hydrogen sulfide $\left(\mathrm{H}_{2} \mathrm{~S}\right)$ has been recognized as a physiological mediator with a variety of functions across all domains of life. In this study, mechanisms of endogenous $\mathrm{H}_{2} \mathrm{~S}$ generation in Shewanella oneidensis were investigated. As a research model with highly diverse anaerobic respiratory pathways, the microorganism is able to produce $\mathrm{H}_{2} \mathrm{~S}$ by respiring on a variety of sulfur-containing compounds with SirACD and PsrABC enzymatic complexes, as well as through cysteine degradation with three enzymes, MdeA, SO_1095, and SseA. We showed that the SirACD and PsrABC complexes, which are predominantly, if not exclusively, responsible for $\mathrm{H}_{2} \mathrm{~S}$ generation via respiration of sulfur species, do not interplay with each other. Strikingly, a screen for regulators controlling endogenous $\mathrm{H}_{2} \mathrm{~S}$ generation by transposon mutagenesis identified global regulator $\mathrm{Crp}$ to be essential to all $\mathrm{H}_{2} \mathrm{~S}$-generating processes. In contrast, Fnr and Arc, two other global regulators that have a role in respiration, are dispensable in regulating $\mathrm{H}_{2} \mathrm{~S}$ generation via respiration of sulfur species. Interestingly, Arc is involved in the $\mathrm{H}_{2} \mathrm{~S}$ generation through cysteine degradation by repressing expression of the $m d e A$ gene. We further showed that expression of the sirA and psrABC operons is subjected to direct regulation of Crp, but the mechanisms underlying the requirement of Crp for $\mathrm{H}_{2} \mathrm{~S}$ generation through cysteine degradation remain elusive.

Keywords: $\mathrm{H}_{2} \mathrm{~S}$, endogenous generation, regulation, Crp, Shewanella

\section{Introduction}

Hydrogen sulfide $\left(\mathrm{H}_{2} \mathrm{~S}\right)$, traditionally recognized as a noxious gas, is now regarded as an important signaling molecule along with nitric oxide (NO) and carbon monoxide (CO), associated with beneficial functions in mammals from vasorelaxation, cardioprotection, and neurotransmission to anti-inflammation (Wang, 2012). In bacteria, investigations into its physiological roles just began. It has been recently elucidated that $\mathrm{H}_{2} \mathrm{~S}$ confers bacterial cells defense against antibiotics by stimulating the cellular protection system against reactive oxygen species (ROS) (Shatalin et al., 2011). Beyond this, our understanding of the mechanism by which $\mathrm{H}_{2} \mathrm{~S}$ affects biology is limited. In both eukaryotes and prokaryotes, $\mathrm{H}_{2} \mathrm{~S}$ can be produced endogenously via assimilatory sulfate reduction and cysteine degradation. $\mathrm{H}_{2} \mathrm{~S}$ of a very small amount formed via the former is rapidly assimilated into organic sulfur compounds such as sulfur-containing amino acids and is hardly released into extracellular environments. On the contrary, the latter, catalyzed by cystathionine $\beta$-synthase (CBS), cystathionine $\gamma$-lyase (CSE), and 3-mercaptopyruvate sulfurtransferase (3MST) together with cysteine aminotransferase (CAT), is responsible for $\mathrm{H}_{2} \mathrm{~S}$ generation on a large scale, ensuring that the molecule can be functionally implicated in many physiological processes 
(Shatalin et al., 2011; Kimura, 2014). Most, if not all, of bacterial genomes encode some of these enzymes. For example, Bacillus anthracis, Pseudomonas aeruginosa, and Staphylococcus aureus have the CBS/CSE operon but not 3MST, whereas Escherichia coli carries 3MST, but not CBS/CSE (Shatalin et al., 2011).

Some prokaryotes have an additional route for $\mathrm{H}_{2} \mathrm{~S}$ generation on a large scale, the dissimilatory sulfate/sulfite $\left(\mathrm{SO}_{4}^{2-} / \mathrm{SO}_{3}^{2-}\right)$ reduction, which is best illustrated in sulfatereducing bacteria (SRB) Desulfovibrio vulgaris (Bradley et al., 2011). The dissimilatory sulfite reductases, featuring siroheme and $[4 \mathrm{Fe}-4 \mathrm{~S}]$ prosthetic centers, are minimally composed of two subunits (DsrA and DsrB) in an $\alpha_{2} \beta_{2}$ arrangement and catalyze the six-electron reduction of sulfite to sulfide (Oliveira et al., 2008). In addition, two other enzyme complexes, represented by PsrABC of Salmonella enterica Serovar Typhimurium and SirACD of Shewanella oneidensis, have been identified to be able to reduce various inorganic sulfur species to $\mathrm{H}_{2} \mathrm{~S}$ (Heinzinger et al., 1995; Shirodkar et al., 2011). The former is able to use as electron acceptors (EAs) thiosulfate $\left(\mathrm{S}_{2} \mathrm{O}_{3}^{2-}\right)$, tetrathionate $\left(\mathrm{S}_{4} \mathrm{O}_{6}^{2-}\right)$, and elemental sulfur $\left(\mathrm{S}^{0}\right)$ for respiration while the latter, which shares similarities with the formate-dependent nitrite reductase, catalyzes direct conversion of sulfite to sulfide. PsrC and SirD serve as quinol oxidases that transfer electrons stepwise via PsrB and SirC to the catalytic subunit PsrA and SirA for reduction of corresponding EAs, respectively (Jormakka et al., 2008; Cordova et al., 2011).

S.oneidensis, a facultative Gram-negative $\gamma$-proteobacterium, has been intensively studied owing to its exceptional metabolic flexibility and its potential use for the bioremediation of metal/radionuclide contaminants in the environment (Fredrickson et al., 2008). Although the microorganism neither belongs to SRB phylogenetically nor possesses analogs of DsrAB, under anaerobic conditions it generates $\mathrm{H}_{2} \mathrm{~S}$ from various sulfur compounds including thiosulfate, sulfite, tetrathionate, and elemental sulfur, a feature firstly revealed more than two and half decades ago (Myers and Nealson, 1988). However, the enzymatic foundation for the reduction was not revealed until recently (Burns and DiChristina, 2009; Shirodkar et al., 2011). In addition to SirACD mentioned above, S.oneidensis also relies on a thiosulfate and polysulfide reductase (PsrABC), homologous to that from S. enterica Serovar Typhimurium (Heinzinger et al., 1995). Based on available genome sequences, it is clear that most of Shewanella species, if not all, are able to produce $\mathrm{H}_{2} \mathrm{~S}$ endogenously via respiration of sulfur species (Gao et al., 2010a).

Most recently, endogenous $\mathrm{H}_{2} \mathrm{~S}$ production has been linked to iron reduction in S. oneidensis and Sulfurospirillum deleyianum (Flynn et al., 2014; Lohmayer et al., 2014). In alkaline environments containing sulfur species and iron compounds, these bacteria first generates $\mathrm{H}_{2} \mathrm{~S}\left(\mathrm{HS}^{-}\right)$, which subsequently reduces iron compounds abiotically (Flynn et al., 2014), indicating an essential role of $\mathrm{H}_{2} \mathrm{~S}$ in bacterial metal reduction under certain conditions. In contrast to the beneficial role, Shewanellae are increasingly being implicated as human pathogens in individuals exposed through occupational or recreational activities to marine niches where these species thrive (Janda and Abbott, 2014). Additionally, Shewanella have been recognized as spoilage bacteria of food (especially marine products) and associated with foul odors, which are in part attributed to endogenous $\mathrm{H}_{2} \mathrm{~S}$ (Janda and Abbott, 2014).

Hence, understanding endogenous $\mathrm{H}_{2} \mathrm{~S}$ production would not only provide insights into biogeochemical redox processes related to metal reduction, but also help to deter and mitigate the emerging threat to human health. In this study, we made efforts to provide a relatively comprehensive understanding of endogenous $\mathrm{H}_{2} \mathrm{~S}$ production and regulation in S.oneidensis. We found that the bacterium possesses a large set of enzymes catalyzing $\mathrm{H}_{2} \mathrm{~S}$ generation through cysteine degradation in addition to anaerobic respiration of sulfurcontaining compounds. While respiration predominantly, if not exclusively, relies on the SirACD and PsrABC complexes there is no interplay with each other. We showed that global regulator Crp (cyclic-AMP receptor protein) but not Fnr (fumarate nitrate regulator) or Arc (aerobic respiration control) is essential to $\mathrm{H}_{2} \mathrm{~S}$ generation via anaerobic respiration. Additionally, we found that both Crp and Arc are involved in $\mathrm{H}_{2} \mathrm{~S}$ generation through cysteine degradation. While it is clear that Arc exerts its impact on the process by repressing expression of the major contributor, the mechanisms underlying the requirement of Crp remain unknown.

\section{Methods and Materials}

\section{Bacterial Strains, Plasmids, and Culture Conditions}

A list of all bacterial strains and plasmids used in this study is given in Table 1. All chemicals were acquired from Sigma Co. (Shanghai, China) unless otherwise noted. Information for primers used in this study is available upon request. For genetic manipulation, E. coli and S. oneidensis strains under aerobic conditions were grown in Lysogeny Broth (LB, Difco, Detroit, MI) medium (Bertani, 2004), which was modified to contain tryptone $(10 \mathrm{~g} / \mathrm{L})$, yeast extract $(5 \mathrm{~g} / \mathrm{L})$, and $\mathrm{NaCl}(5 \mathrm{~g} / \mathrm{L})$, at 37 and $30^{\circ} \mathrm{C}$, respectively. When needed, the growth medium was supplemented with chemicals at the following concentrations: 2,6-diaminopimelic acid (DAP), $0.3 \mathrm{mM}$; ampicillin sodium, $50 \mu \mathrm{g} / \mathrm{ml}$; kanamycin sulfate, $50 \mu \mathrm{g} / \mathrm{ml}$; and gentamycin sulfate; $15 \mu \mathrm{g} / \mathrm{ml}$.

\section{Physiological Characterization of S. oneidensis Strains}

M1 defined medium containing $0.02 \%(\mathrm{w} / \mathrm{v})$ of vitamin free casamino acids and $20 \mathrm{mM}$ lactate was used as described previously (Gao et al., 2008). Growth of S. oneidensis strains under aerobic or anaerobic conditions was determined by recording optical densities of $600 \mathrm{~nm}\left(\mathrm{OD}_{600}\right)$ of cultures. For aerobic growth, fresh media were inoculated to $\sim 0.01$ of $\mathrm{OD}_{600}$ with overnight cultures grown from a single colony. For anaerobic growth, exponential phase cultures grown aerobically were centrifuged, washed with fresh medium twice, purged in nitrogen and suspended in fresh medium to $\sim 0.01$ of $\mathrm{OD}_{600}$ in an anaerobic glove box. To cultivate $\Delta c r p$ and $\Delta c y a C$ under anaerobic conditions, Trimethylamine N-oxide (TMAO) was used as growth supporting EA. EAs were used at the concentration of $10 \mathrm{mM}$ unless otherwise noted. 
TABLE 1 | Strains and plasmids used in this study.

\begin{tabular}{|c|c|c|}
\hline Strain or plasmid & Description & Reference or source \\
\hline \multicolumn{3}{|l|}{ E. coli STRAINS } \\
\hline $\mathrm{DH} 5 \alpha$ & Host strain for plasmids & Lab stock \\
\hline WM3064 & $\begin{array}{l}\text { Donor strain for conjugation; } \\
\Delta d a p A\end{array}$ & W. Metcalf, UIUC \\
\hline XL1-Blue MRF'Kan & $\begin{array}{l}\text { Recipient strain for } \\
\text { two-hybrid system }\end{array}$ & Stratagene \\
\hline \multicolumn{3}{|c|}{ S. oneidensis STRAINS } \\
\hline MR-1 & Wild-type & ATCC 700550 \\
\hline HG0479 & $\Delta$ sirA derived from MR-1 & This study \\
\hline HG0624 & $\Delta c r p$ derived from MR-1 & Gao et al., 2010b \\
\hline HG1095 & $\begin{array}{l}\Delta \mathrm{SO}_{-} 1095 \text { derived from } \\
\mathrm{MR}-1\end{array}$ & This study \\
\hline HG1261 & $\Delta s s e A$ derived from MR-1 & This study \\
\hline HG1329 & $\Delta c y a C$ derived from MR-1 & This study \\
\hline HG1812 & $\Delta m d e A$ derived from MR-1 & This study \\
\hline HG2191 & $\Delta m e t C$ derived from MR-1 & This study \\
\hline HG2356 & $\Delta f n r$ derived from MR-1 & Gao et al., 2010b \\
\hline HG2903 & $\Delta c y s K$ derived from MR-1 & This study \\
\hline HG3598 & $\Delta c y s M$ derived from MR-1 & This study \\
\hline HG3988 & $\triangle a r c A$ derived from MR-1 & Gao et al., 2008 \\
\hline HG4056 & $\Delta$ met $B$ derived from MR-1 & This study \\
\hline HG4062 & $\Delta p s r A$ derived from MR-1 & This study \\
\hline HG1095-1812 & $\begin{array}{l}\Delta m d e A \Delta S S_{-} 1095 \text { derived } \\
\text { from } M R-1\end{array}$ & This study \\
\hline HG1261-1812 & $\begin{array}{l}\Delta m d e A \Delta s s e A \text { derived from } \\
\text { MR-1 }\end{array}$ & This study \\
\hline HG0479-4062 & $\begin{array}{l}\Delta s i r A \Delta p s r A \text { derived from } \\
\text { MR-1 }\end{array}$ & This study \\
\hline HG1329-4312 & $\begin{array}{l}\Delta \text { cyaC } \triangle \text { cyaA derived from } \\
\text { MR-1 }\end{array}$ & This study \\
\hline \multicolumn{3}{|l|}{ PLASMIDS } \\
\hline pHGM01 & $\begin{array}{l}\mathrm{Ap}{ }^{R}, \mathrm{Gm}^{\mathrm{R}}, \mathrm{CM}^{\mathrm{R}} \text {, suicide } \\
\text { vector }\end{array}$ & Jin et al., 2013 \\
\hline pHG101 & $\begin{array}{l}\text { Promoterless broad-host } \\
\mathrm{Km}^{R} \text { vector }\end{array}$ & Wu et al., 2011 \\
\hline pHG102 & $\begin{array}{l}\text { pHG101 containing the } S \text {. } \\
\text { oneidensis arcA promoter }\end{array}$ & Wu et al., 2011 \\
\hline pHGT01 & $\begin{array}{l}\text { Promoter-embedded } \\
\text { Mariner-based transposon } \\
\text { vector }\end{array}$ & Yin et al., 2015 \\
\hline pBXcmT & $\mathrm{B} 1 \mathrm{H}$ bait vector & Guo et al., 2009 \\
\hline pTRG & $\mathrm{B} 1 \mathrm{H}$ target vector & Stratagene \\
\hline $\mathrm{pBX} c m \mathrm{~T}-\mathrm{P}_{\text {cyd }}$ & Positive control bait vector & Jiang et al., 2014 \\
\hline $\mathrm{pBX} \mathrm{XmT}^{-} \mathrm{P}_{16 \mathrm{~s}}$ & Negative control bait vector & Li et al., 2014 \\
\hline pTRG-Crp & $\begin{array}{l}\mathrm{B} 1 \mathrm{H} \text { target vector } \\
\text { expressing crp }\end{array}$ & Jiang et al., 2014 \\
\hline pHGEI01 & $\begin{array}{l}\text { Integrative lacZ reporter } \\
\text { vector }\end{array}$ & Fu et al., 2014 \\
\hline pBBR-Cre & $\begin{array}{l}\text { Helper vector for antibiotic } \\
\text { marker removal }\end{array}$ & Fu et al., 2013 \\
\hline
\end{tabular}

\section{Mutagenesis and Genetic Complementation}

S. oneidensis in-frame deletion strains were constructed using the att-based Fusion PCR method (Jin et al., 2013). In brief, two fragments flanking the target gene were generated by PCR with primers containing attB and the gene specific sequence, and then were joined by a second round of PCR. The fusion fragments were introduced into plasmid pHGM01 by site-specific recombination using the BP Clonase (Invitrogen) according to the manufacturer's instruction. The resulting mutagenesis vectors were transformed into E. coli WM3064 and the verified ones were transferred into proper $S$. oneidensis strains via conjugation. Integration of the mutagenesis constructs into the chromosome were selected by resistance to gentamycin and confirmed by PCR. Verified transconjugants were grown in LB broth in the absence of $\mathrm{NaCl}$ and plated on LB supplemented with $10 \%$ sucrose. Gentamycin-sensitive and sucrose-resistant colonies were screened by PCR for the intended deletion. All mutations were verified by sequencing the mutated regions.

Mutants from previous studies were successfully complemented by using either multiple-copy or singlecopy (integrative) vectors (Table 1). In this study, the same complementation constructs were used and similar results were obtained as indicated in the figure legends. For newly constructed mutants, plasmids pHG101 and pHG102 were utilized for genetic complementation (Wu et al., 2011). For genes adjacent to their promoter, a fragment containing the gene of interest and its native promoter was generated by PCR and cloned into pHG101. For others, the gene of interest was amplified and inserted into the multiple-cloning site (MCS) of pHG102 under the control of the $\operatorname{arcA}$ promoter, which is constitutively active (Gao et al., 2010b). After verified by sequencing, the resulting complementation vector was transferred into its relevant mutant strains via conjugation.

\section{$\mathrm{H}_{2} \mathrm{~S}$ Detection}

$\mathrm{H}_{2} \mathrm{~S}$ generation in $\mathrm{S}$. oneidensis strains was monitored by using a lead acetate detection method (Shatalin et al., 2011). Paper strips saturated by $2 \%$ of $\mathrm{Pb}(\mathrm{Ac})_{2}$ were affixed to the inner wall of a cultural tube, above the level of the liquid culture. Overnight cultures were used to inoculate fresh LB media to $\sim 0.01$ of $\mathrm{OD}_{600}$ and incubated for $\sim 20 \mathrm{~h}$ at $30^{\circ} \mathrm{C}$ with aeration. Stained paper strips were scanned and quantified with a UVP HR410 Imaging System (UVP). The results were normalized to $\mathrm{OD}_{600}$ readings. $\mathrm{H}_{2} \mathrm{~S}$ concentrations in liquid cultures grown under aerobic and anaerobic conditions were quantified by using the methylene blue formation assay (Siegel, 1965). In brief, properly diluted aliquots $(1.6 \mathrm{ml})$ were mixed with $0.2 \mathrm{ml}$ DPD $(20 \mathrm{mM}$ $N, N$-dimetyl-p-phenylenediamine sulfate in $7.2 \mathrm{M} \mathrm{HCl}$ ) and $0.2 \mathrm{ml} \mathrm{FeCl}_{3}\left(30 \mathrm{mM} \mathrm{FeCl}_{3}\right.$ in $\left.1.2 \mathrm{M} \mathrm{HCl}\right)$. After $30 \mathrm{~min}$ at $25^{\circ} \mathrm{C}$, the absorbance at $667 \mathrm{~nm}$ was measured and related to sulfide concentration using calibration curves generated with NaHS.

\section{Transposon Mutagenesis}

A random transposon-insertion library was constructed with pHGT01, a mariner-based transposon vector which carries an embedded promoter within the transposable fragment (Fu et al., 2013; Yin et al., 2015). When mutants were grown in LB containing $\mathrm{SO}_{3}^{2-}, \mathrm{S}_{2} \mathrm{O}_{3}^{2-}$, and cysteine at $2 \mathrm{mM}$ to the late exponential phase in 96-well plates, the lids of the plates were removed to let out gaseous $\mathrm{H}_{2} \mathrm{~S}$, and $1 \mathrm{~h}$ later the $\mathrm{H}_{2} \mathrm{~S}$ levels of cultures in each well were visualized with paper strips saturated by $2 \%$ of $\mathrm{Pb}(\mathrm{Ac})_{2}$. Mutants exhibiting significant reduction in $\mathrm{H}_{2} \mathrm{~S}$ generation were saved and then cultured in individual 
tubes for verification. The confirmed mutants were subjected to arbitrary PCR for mapping the transposon insertion sites (Das et al., 2005).

\section{B1H Assay}

Bacterial one-hydrid system was used to investigate DNA-protein interaction in vivo in E. coli cells (Guo et al., 2009). Briefly, plasmid constructs were created by cloning the bait DNA and target Crp into the pBXcmT and pTRG vectors, respectively, and verified by sequencing. The resultant plasmids were used to cotransform BacterioMatch II Validation Reporter Competent Cells on M9 salt agar plates containing $25 \mathrm{mg} / \mathrm{ml}$ chloramphenicol and $12.5 \mathrm{mg} / \mathrm{ml}$ tetracycline with or without 3-AT. A pair of

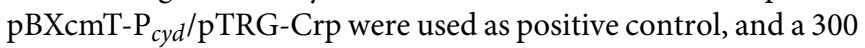
bp DNA fragment of the 16s rRNA gene promoter (pBXcmT$\mathrm{P}_{16 s}$ ) was used as negative control (Jiang et al., 2014; Li et al., 2014). The plates were incubated for $24 \mathrm{~h}$ and then moved to room temperature for an additional $16 \mathrm{~h}$ (colonies indicating positive interaction usually appeared between 18 and $24 \mathrm{~h}$ ). The positive interactions were confirmed by streaking colonies on plates containing both $3-\mathrm{AT}$ and streptomycin $(12.5 \mathrm{mg} / \mathrm{ml})$.

\section{Expression Analyses}

To prepare samples for expression analyses, cultures at the midlog phase were aliquotted; an aliquot was used as the untreated control and other aliquots were added with chemicals indicated in the text, and then collected $30 \mathrm{~min}$ post-addition. In total, four biological replicates under each condition were collected for the analyses. Levels of gene expression were determined by using an integrative lac $Z$-reporter system and $\beta$-Galactosidase activity assay, as performed essentially the same as before (Fu et al., 2014; Jiang et al., 2014). In addition, levels of mRNAs were also assayed using Quantitative RT-PCR (qRT-PCR) with an ABI7300 96-well qRT-PCR system (Applied Biosystems) as described previously (Yuan et al., 2011).

\section{Other Analyses}

DNA and protein sequence similarity searches were performed using the BLAST program. Sequences of proteins of interest for alignments were obtained from Genbank. Alignments were performed using Clustal Omega (http://www.ebi.ac.uk/ Tools/msa/clustalo). Promoter prediction for genes of interest was performed by using the Neural Network Promoter Prediction program (Reese, 2001). Experimental values are subjected to statistical analyses and presented as means \pm SD (standard deviation). Student's $t$-test was performed for pairwise comparisons of groups.

\section{Results}

\section{MdeA is the Major Contributor for $\mathrm{H}_{2} \mathrm{~S}$ Generation Under Aerobic Conditions}

Given that the assimilatory reduction of sulfite usually does not release $\mathrm{H}_{2} \mathrm{~S}$ into the environment, endogenous $\mathrm{H}_{2} \mathrm{~S}$ at physiologically relevant levels in cultures is predominantly produced by reductases reducing sulfur-containing compounds and orthologs of mammalian $\mathrm{H}_{2} \mathrm{~S}$ generation enzymes (cysteine degradation), including CBS, CSE, and 3MST (Shatalin et al., 2011; Keseler et al., 2013) (Figure S1). In S. oneidensis, thiosulfate and polysulfite reductase PsrABC and sulfite reductase SirACD are known to be responsible for $\mathrm{H}_{2} \mathrm{~S}$ generation under anaerobic conditions (Burns and DiChristina, 2009; Shirodkar et al., 2011). In contrast, the pathways for $\mathrm{H}_{2} \mathrm{~S}$ generation through the cysteine degradation pathway remain veiled. To identify orthologs of mammalian cysteine degradation enzymes, we performed BLASTp screening using E. coli 3MST and $P$. aeruginosa CBS and CSE against the $S$. oneidensis proteome. Results showed that the genome encodes a set of high confidence hits for these three proteins (Table S1 and Figure S2). Multiple orthologs of high confidence for CBS (CysM and CysK) and CSE (MetB, MdeA, SO_1095, and MetC) are present while there is only one for 3MST (SseA). This is not surprising given that the E. coli genome also encodes several proteins homologous to these three enzymes (Shatalin et al., 2011). However, it is common that only a portion of the homologous proteins are enzymes involved in $\mathrm{H}_{2} \mathrm{~S}$ generation, based on the findings from $E$. coli, B. anthracis, $P$. aeruginosa, and $S$. aureus (Shatalin et al., 2011). To assess the contribution of the predicted enzymes in $\mathrm{H}_{2} \mathrm{~S}$ generation through cysteine degradation under aerobic conditions, we inactivated each set of enzymes chemically using their specific inhibitors: amino-oxyacetate (AOAA) for CBS, asparate (Asp) for 3MST, and DL-propargylglycine (PAG) for CSE (Shatalin et al., 2011). $\mathrm{H}_{2} \mathrm{~S}$ generation was detected using lead acetate $\left[\mathrm{Pb}(\mathrm{Ac})_{2}\right]$, which can specifically react with $\mathrm{H}_{2} \mathrm{~S}$ to form brown-colored precipitate of lead sulfide [PbS], whose amount is proportional to the concentration of $\mathrm{H}_{2} \mathrm{~S}$. As shown in Figure 1A, effects of these inhibitors on $\mathrm{H}_{2} \mathrm{~S}$ generation varied significantly. Compared to the non-inhibitor control culture, addition of $7.5 \mathrm{mM}$ PAG nearly eliminated $\mathrm{PbS}$ staining $(<10 \%)$ and Asp had a rather mild impact on $\mathrm{H}_{2} \mathrm{~S}$ generation, manifesting contribution of CSE and 3MST in $\mathrm{H}_{2} \mathrm{~S}$ generation. In contrast, addition of AOAA increased $\mathrm{H}_{2} \mathrm{~S}$ generation significantly, implicating that the CBS homologs do not function as cystathionine $\beta$-synthase. To confirm that CSE is the major source of $\mathrm{H}_{2} \mathrm{~S}$ generation, we assessed the effects of PAG of various concentrations. As expected, the amounts of $\mathrm{H}_{2} \mathrm{~S}$ produced were inversely proportional to the concentrations of the inhibitor (Figure 1B). In parallel, $\mathrm{H}_{2} \mathrm{~S}$ generation was also quantified in liquid static media in 24-well plates by using the methylene blue formation assay (Siegel, 1965). We found that data from these two methods were comparable in general. In the rest of the study, the methylene blue formation assay was chosen because it is more sensitive and easier for quantification.

To decisively determine roles of these enzymes in $\mathrm{H}_{2} \mathrm{~S}$ generation under aerobic conditions, we constructed a set of mutants that lack one of these enzymes and monitored $\mathrm{H}_{2} \mathrm{~S}$ production in the resulting mutants (Figure 1C). All mutants were indistinguishable from the wild-type with respect to growth under aerobic or anaerobic conditions with fumarate as the sole EA (data not shown). Among all mutants, the $\Delta c y s K$ strain stood out as it produced substantially more $\mathrm{H}_{2} \mathrm{~S}$ than the wild-type. This phenotype, similar to that resulting from the addition of AOAA, was confidently attributed to the cysK mutation after successful genetic complementation. The result, 

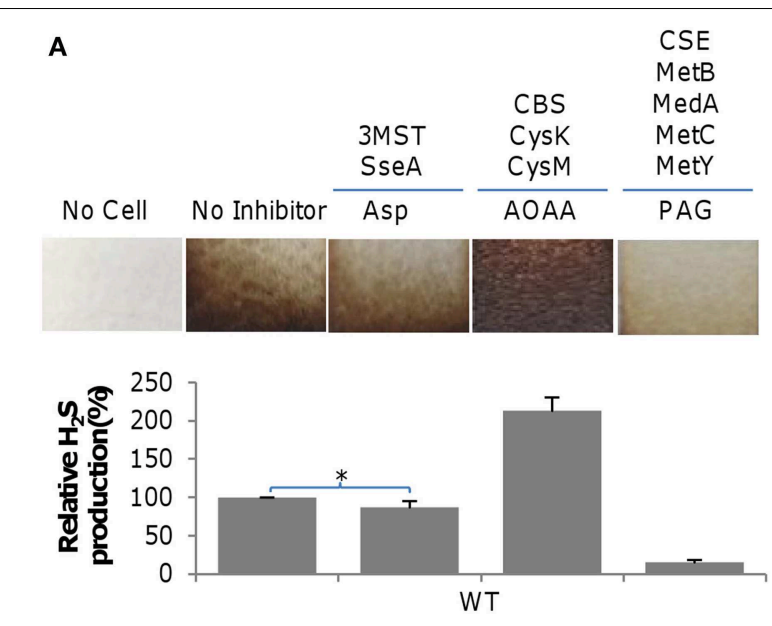

B
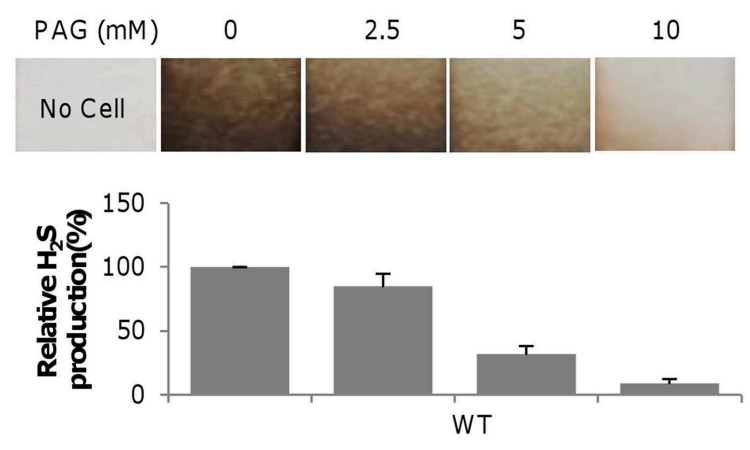

C

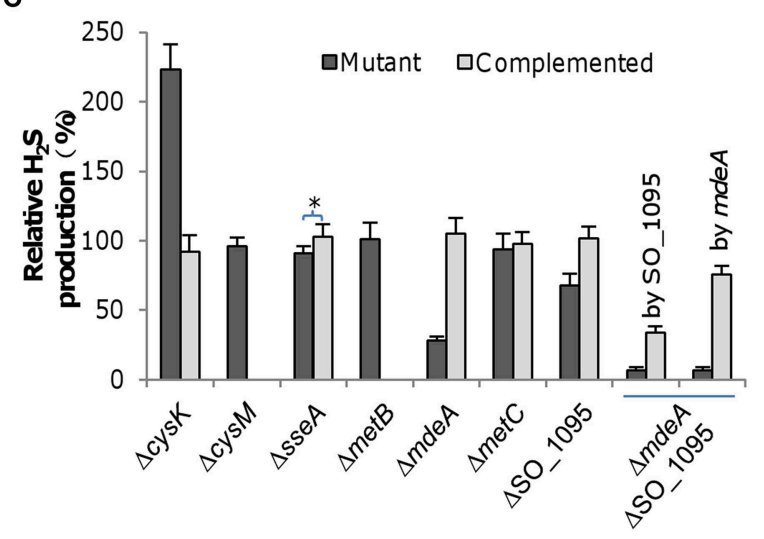

FIGURE 1 | $\mathbf{H}_{\mathbf{2}} \mathbf{S}$ generation by S. oneidensis. (A) Effects of Asp ( $3 \mathrm{mM}$ ), AOAA $(50 \mu \mathrm{M})$, and PAG $(7.5 \mathrm{mM})$, inhibitors of $3 \mathrm{MST}$, CBS, and CSE respectively, on $\mathrm{H}_{2} \mathrm{~S}$ generation by the $\mathrm{S}$. oneidensis wild-type. (B) Effects of PAG, the CSE inhibitor, at varying concentrations on $\mathrm{H}_{2} \mathrm{~S}$ generation by the $S$. oneidensis wild-type. (C) $\mathrm{H}_{2} \mathrm{~S}$ generation by indicated $\mathrm{S}$. oneidensis mutants. Mutants showing a significant defect in $\mathrm{H}_{2} \mathrm{~S}$ generation were subjected to genetic complementation. The double mutant $\left(\Delta m d e A \Delta S O \_1095\right)$ was complemented by either gene separately. Lead acetate-soaked paper strips show a PbS brown or black stain as a result of reaction with $\mathrm{H}_{2} \mathrm{~S}$. Strips were affixed to the inner wall of a culture tube, above the level of the liquid cultures for $\sim 20 \mathrm{~h}$. Levels of the wild-type were averaged and set to be $100 \%$, and used to normalize averaged $\mathrm{H}_{2} \mathrm{~S}$ levels of all other samples. In (C), the methylene blue formation assay was used for quantification of $\mathrm{H}_{2} \mathrm{~S}$. Data are presented as the mean $\pm S D$ from at least five independent experiments. Asterisks indicate statistically significant difference $\left({ }^{*}, p<0.05\right)$. however, is not surprising because CysK primarily catalyzes the synthesis of L-cysteine from O-acetyl-L-serine and $\mathrm{H}_{2} \mathrm{~S}$ although it has also been implicated in $\mathrm{H}_{2} \mathrm{~S}$ generation (Byrne et al., 1988) (Figure S1). Consistent with the effect of Asp, a mutational analysis of the sseA gene revealed that the protein had a negligible role in $\mathrm{H}_{2} \mathrm{~S}$ generation. In the case of CSE analogs, MetB and MetC appeared to be dispensable for $\mathrm{H}_{2} \mathrm{~S}$ generation, a scenario agreeing with their annotated functions (Figure S1). In contrast, loss of either MdeA or SO_1095 resulted in drastic reduction in $\mathrm{H}_{2} \mathrm{~S}$ generation, indicating that these two proteins are major contributors for releasing endogenous $\mathrm{H}_{2} \mathrm{~S}$. Apparently, MdeA is the most important enzyme for the task in $S$. oneidensis, accountable for at least $70 \%$ of $\mathrm{H}_{2} \mathrm{~S}$ generation under test conditions. The involvement of MdeA, a methionine $\gamma$-lyase, in the process is reasonable because it converts L-cysteine and $\mathrm{H}_{2} \mathrm{O}$ to pyruvate, $\mathrm{NH}_{3}$, and $\mathrm{H}_{2} \mathrm{~S}$ (Figure S1) (Sato and Nozaki, 2009). However, it is not immediately evident why $\mathrm{SO}_{-} 1095$ contributes to $\mathrm{H}_{2} \mathrm{~S}$ generation given that its predicted role as $\mathrm{O}$-acetylhomoserine (thiol)-lyase is not related to any known pathway for $\mathrm{H}_{2} \mathrm{~S}$ generation. The observed phenotypes of reduced $\mathrm{H}_{2} \mathrm{~S}$ generation resulting from the $m d e A$ and $\mathrm{SO}_{-} 1095$ deletions were corrected by their expression in trans, validating the linkage between the phenotypes and corresponding mutations. To further confirm that MdeA and SO_1095 are enzymes predominantly responsible for endogenous $\mathrm{H}_{2} \mathrm{~S}$ generation in $\mathrm{S}$. oneidensis, we constructed a strain lacking both the mdeA and SO_1095 genes. Not surprisingly, the double removal further compromised the capacity of $\mathrm{H}_{2} \mathrm{~S}$ generation (Figure 1C). These data, collectively, indicate that in S. oneidensis MdeA and SO_1095 dictate endogenous $\mathrm{H}_{2} \mathrm{~S}$ generation.

\section{$\mathrm{H}_{2} \mathrm{~S}$ Generation Pathways with MdeA and SseA are Cysteine-inducible}

The primary source of endogenous $\mathrm{H}_{2} \mathrm{~S}$ is L-cysteine; as a consequence, many processes leading to $\mathrm{H}_{2} \mathrm{~S}$ generation are subjected to induction by the amino acid (Shatalin et al., 2011). To determine which enzymes are cysteine-inducible, we measured the $\mathrm{H}_{2} \mathrm{~S}$ generation capacity of $S$. oneidensis strains with cysteine. In the presence of $10 \mathrm{mM}$ cysteine, there was an increase of $\sim 2.8$-fold in $\mathrm{H}_{2} \mathrm{~S}$ generation in the wild-type (Figure 2A). Similar results were obtained from mutant strains in which mutations do not show any noticeable impact on $\mathrm{H}_{2} \mathrm{~S}$ generation, confirming that these genes are not involved in the process. Additionally, induction to comparable levels by L-cysteine was also observed in the $\Delta s s e A$ and $\Delta$ SO_$_{-} 1095$, supporting that MdeA is the enzyme responsible for increased $\mathrm{H}_{2} \mathrm{~S}$ generation. In both the $\Delta m d e A$ and $\Delta m d e A \Delta \mathrm{SO}_{-} 1095$ strains, the induction decreased to similar levels, implicating that SO_1095 may not be subjected to induction by L-cysteine. Rather, this induction is likely attributed to SseA. To test it, we generated an $m d e A$ and sseA double mutant $(\Delta m d e A \Delta s s e A)$ and assayed its capacity of $\mathrm{H}_{2} \mathrm{~S}$ generation (Figure 2A). In the absence of cysteine, the mutant generated $\mathrm{H}_{2} \mathrm{~S}$ at a level similar to that from the mdeA single mutant. Addition of cysteine did not result in any increase in $\mathrm{H}_{2} \mathrm{~S}$ generation, indicating that the mutant is reluctant to respond to exogenous cysteine. These data manifest 

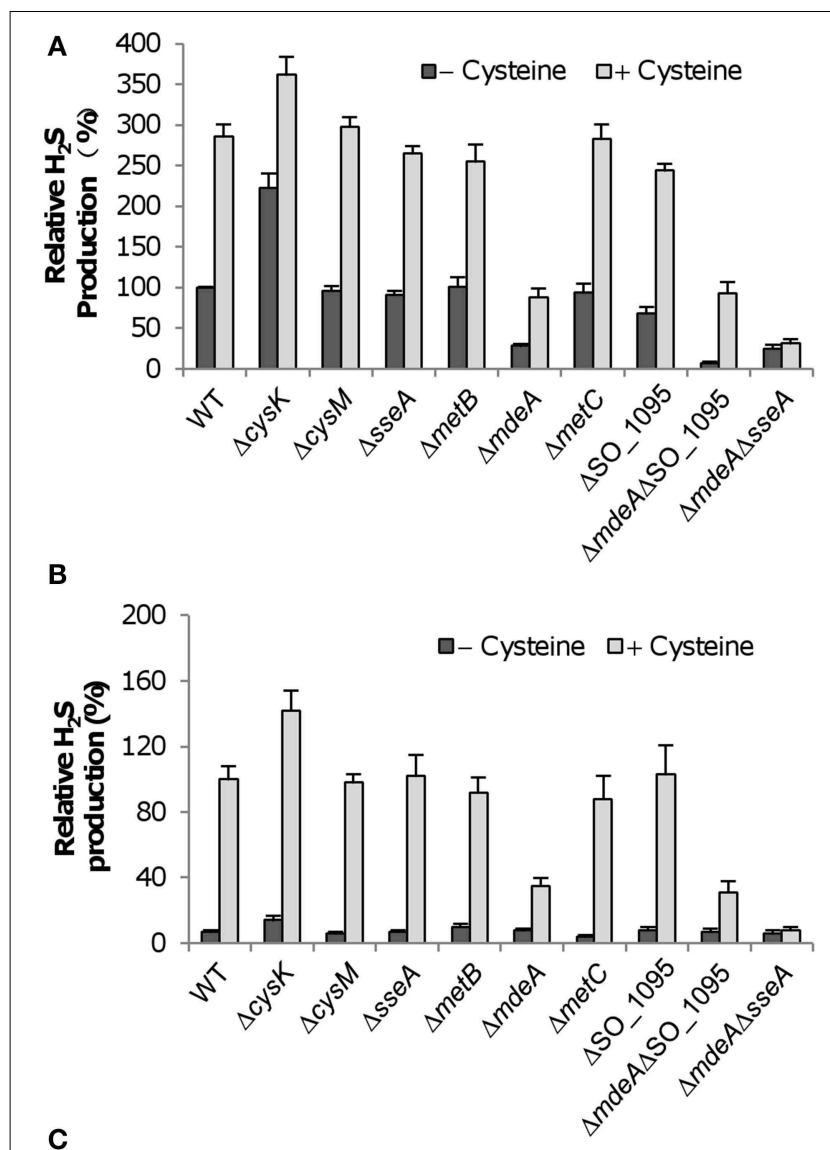

C

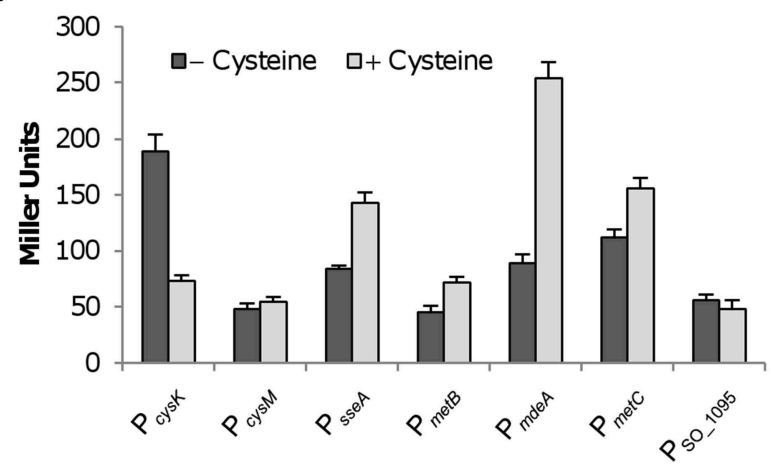

FIGURE 2 | Effect of cysteine on S. oneidensis strains. (A) Effect of $10 \mathrm{mM}$ cysteine on $\mathrm{H}_{2} \mathrm{~S}$ generation by $\mathrm{S}$. oneidensis strains under aerobic conditions. Averaged $\mathrm{H}_{2} \mathrm{~S}$ level of the wild-type in the absence of cysteine was set to $100 \%$ for subsequent normalization. (B) Effect of $10 \mathrm{mM}$ cysteine on $\mathrm{H}_{2} \mathrm{~S}$ generation by $S$. oneidensis strains under anaerobic conditions. Fumarate was used as the sole EA. Averaged $\mathrm{H}_{2} \mathrm{~S}$ level of the wild-type in the presence of cysteine was set to $100 \%$ for subsequent normalization because $\mathrm{H}_{2} \mathrm{~S}$ levels were extremely low without induction. (C) Effect of $10 \mathrm{mM}$ cysteine on activities of indicated promoters. For each test gene, the promoter-lacZ (E. coli) construct was introduced into the chromosome of the wild-type and the activities of the promoter as single copy were assessed by $\beta$-galactosidase assay. Data are presented as the mean $\pm \mathrm{SD}$ from at least three independent experiments.

that SseA becomes a significant contributor for $\mathrm{H}_{2} \mathrm{~S}$ generation under induced conditions.

$\mathrm{H}_{2} \mathrm{~S}$ generation through cysteine degradation is supposed to be independent of EAs for respiration. We therefore reasoned that the induction of $\mathrm{H}_{2} \mathrm{~S}$ generation by L-cysteine should be observed under anaerobic conditions as well. To test this, the wild-type and mutant strains were assayed for $\mathrm{H}_{2} \mathrm{~S}$ generation with fumarate as the sole EA. As shown in Figure $\mathbf{2 B}, \mathrm{H}_{2} \mathrm{~S}$ was hardly generated in any of these strains in the absence of L-cysteine, most likely because levels of metabolically synthesized substrates for cysteine degradation enzymes are too low to elicit a significant influence on overall $\mathrm{H}_{2} \mathrm{~S}$ generation during growth. When cysteine was supplemented, levels of $\mathrm{H}_{2} \mathrm{~S}$ in cultures of all test strains increased drastically (Figure 2B). Compared to the data obtained from the aerobic cultures, a similar trend was observed, confirming that the activities of MdeA and SseA are EA-independent and cysteine-inducible.

To further investigate into the effect of L-cysteine on $\mathrm{H}_{2} \mathrm{~S}$ generation in $S$. oneidensis, we employed an integrative lacZreporter system pHGEI01 to assess expression of these genes (Fu et al., 2014). The reporter system is characterized by its ability to integrate into the chromosome and a removable antibiotic marker, and thus allows us to avoid complications of antibiotics on growth and of copy numbers of plasmids on lacZ expression. All of these genes are immediately adjacent to the promoters of their residing operons (data not shown). According to the promoter prediction, promoters of the highest confidence for all genes were located within 400 bp upstream of coding sequences (data not shown). We therefore amplified a fragment of $\sim 400$ bp upstream of each gene and inserted it into the multiple cloning site (MCS) before the E. coli lacZ gene in pHGEI01. After integration and antibiotic marker removal, mid-log phase cultures $\left(\sim 0.3\right.$ of $\left.\mathrm{OD}_{600}\right)$ were prepared for the $\beta$-galactosidase assay. Cysteine-treated samples were collected $30 \mathrm{~min}$ after cysteine addition. As shown in Figure 2C, lacZ expression driven by the cysM and SO_1095 promoters fluctuated within a narrow range, indicating that impacts of the addition of cysteine on their expression were negligible. In contrast, expression levels of the cysK, sse $A, \operatorname{met} B$, met $C$, and $m d e A$ genes were significantly different in cultures between the normal and cysteine-induced conditions. Given that cysteine is the product of CysK, reduction in cysK expression is expected upon the addition of the amino acid. The remaining four genes showed increases in their expression levels to varying extent, depending on the gene. Consistent with the data presented in Figure $2 \mathbf{A}$, the sse $A$ and $m d e A$ genes were expressed substantially higher in the treated samples, confirming that SseA and MdeA are cysteine-inducible enzymes involved in $\mathrm{H}_{2} \mathrm{~S}$ generation in $S$. oneidensis. In the case of the met $B$ and met $C$ genes, the induction is not surprising because cysteine is a substrate of the pathway in which they play a role (Figure S1). Moreover, similar results were obtained from an independent examination of expression levels of these genes by using qRT-PCR (Figure S3). Taken together, these data conclude that MdeA is the predominant enzyme for $\mathrm{H}_{2} \mathrm{~S}$ generation from cysteine and SseA makes a significant contribution when cysteine is abundant.

\section{SirACD and PsrABC are Independent of Each Other}

With $\mathrm{SO}_{3}^{2-}, \mathrm{S}^{0}$, and $\mathrm{S}_{2} \mathrm{O}_{3}^{2-}$ as the sole EAs, S. oneidensis is able to generate $\mathrm{H}_{2} \mathrm{~S}$ by using the SirACD and PsrABC complexes, 
respectively (Burns and DiChristina, 2009; Shirodkar et al., 2011). However, whether these two complexes interplay with each other is worth studying given that many sulfur species are enzymatically convertible from one another (Kimura, 2014). To this end, we constructed $\triangle \operatorname{sir} A, \triangle p s r A$, and $\triangle \operatorname{sir} A \Delta p s r A$ strains and compared their capacities of $\mathrm{H}_{2} \mathrm{~S}$ generation to that of the wild-type. When grown on fumarate, $\mathrm{H}_{2} \mathrm{~S}$ generation in the $\Delta \operatorname{sir} A, \triangle p s r A$, and $\triangle \operatorname{sir} A \Delta p s r A$ strains was extremely low, resembling that in the wild-type (Figure 3), implicating that loss of SirACD, PsrABC, or both has no effect on the cysteine degradation pathway under the condition. In the presence of $\mathrm{SO}_{3}^{2-}, \mathrm{H}_{2} \mathrm{~S}$ levels in cultures of the wild-type and $\triangle p s r A$ strains increased dramatically (Figure 3), an observation in excellent agreement with the results of a previous study (Shirodkar et al., 2011). Similarly, robust $\mathrm{H}_{2} \mathrm{~S}$ generation was observed from the wild-type and $\triangle$ sirA strains with $\mathrm{S}_{2} \mathrm{O}_{3}^{2-}$ as the sole EA. In both cases, the $\Delta$ sirA $\Delta p s r A$ strain produced $\mathrm{H}_{2} \mathrm{~S}$ at levels comparable to that of the wild-type grown on fumarate. In the presence of cysteine, $\mathrm{H}_{2} \mathrm{~S}$ generation was further enhanced in the wildtype, suggesting an additive effect from respiration of sulfur species and cysteine degradation, which was also evident in $\triangle$ sirA with $\mathrm{S}_{2} \mathrm{O}_{3}^{2-}$ and in $\triangle p s r A$ with $\mathrm{SO}_{3}^{2-}$. Expression of each of these genes in trans in its corresponding mutant restored $\mathrm{H}_{2} \mathrm{~S}$ generation to the wild-type levels, confirming that the observed phenotypes were due to the intended mutations (Figure S4). These results indicate that the SirACD and PsrABC complexes are fully responsible for dissimilatory $\mathrm{H}_{2} \mathrm{~S}$ generation, and appear functionally independent of each other.

\section{Crp is a Global Regulator Essential for Endogenous $\mathrm{H}_{2} \mathrm{~S}$ Generation}

Given that many enzymes participate in $\mathrm{H}_{2} \mathrm{~S}$ generation simultaneously, we became interested in whether there is a regulator mediating all of the processes in which these enzymes are involved, not necessarily in a direct manner. In our effort to identify such a regulator, we took advantage of transposon-based random mutagenesis. A random mutant library was generated using pHGT01, which allows screening for active operons as well as cryptic ones because of an embedded promoter within the transposable fragment (Fu et al., 2013; Yin et al., 2015). The medium was supplemented with proper amounts of cysteine, $\mathrm{SO}_{3}^{2-}$ and $\mathrm{S}_{2} \mathrm{O}_{3}^{2-}$, such that one of the significant contributors alone can produce a sufficient amount of $\mathrm{H}_{2} \mathrm{~S}$ for being a $\mathrm{H}_{2} \mathrm{~S}$-plus strain. In approximately 10,000 gentamycin-resistant isolates screened, we found $\sim 200$ showing substantial reduction in $\mathrm{H}_{2} \mathrm{~S}$ generation by using $\mathrm{Pb}(\mathrm{Ac})_{2}$-socked paper strips. However, many of them turned out to be false positive during subsequent validation. Among the remaining, two mutants were completely negative in $\mathrm{H}_{2} \mathrm{~S}$ generation whereas three generated $\mathrm{H}_{2} \mathrm{~S}$ at levels just detectable. Insertions in the former two were mapped into the crp gene and in the latter three were mapped into the cyaC gene. In S. oneidensis, Crp is the most important global regulator for both aerobic and anaerobic respiration and is activated by binding to cAMP, whose production mainly depends on membrane-bound adenylate cyclase CyaC (Saffarini et al., 2003; Charania et al., 2009). The insertions found in both crp and $c y a C$ genes strongly suggest that the Crp regulatory system likely plays a crucial role in endogenous $\mathrm{H}_{2} \mathrm{~S}$ generation in this microorganism.

To confirm this, we constructed a cyaC in-frame deletion strain $(\triangle c y a C)$ and examined the $\mathrm{H}_{2} \mathrm{~S}$ generation capacity of the resulting strain, along with a $\operatorname{crp}$ deletion strain $(\Delta c r p)$. The $\mathrm{H}_{2} \mathrm{~S}$ generation assay revealed that the $\Delta \mathrm{crp}$ strain completely lost the ability to produce $\mathrm{H}_{2} \mathrm{~S}$ whereas the $\Delta c y a C$ strain retained residual capacity, approximately $17 \%$ relative to the wild-type when grown with sulfite and thiosulfate anaerobically (Figure 4A). This scenario can be readily explained by the presence of other adenylate cyclases, CyaA and $\mathrm{CyaB}$, the former of which displays a detectable, albeit weak, ability to synthesize cAMP (Charania et al., 2009). Additional removal of the $c y a A$ gene from the $c y a C^{-}$background further reduced $\mathrm{H}_{2} \mathrm{~S}$ generation to a level comparable to that resulting from the crp deletion. Similar results were obtained with cultures grown with $2 \mathrm{mM}$ cysteine under aerobic conditions (Figure 4B), manifesting that Crp is also required for $\mathrm{H}_{2} \mathrm{~S}$ generation from cysteine degradation. The essentiality of Crp to $\mathrm{H}_{2} \mathrm{~S}$ generation from both processes was further supported by similar findings observed from cultures grown with sulfur, thiosulfate, and $2 \mathrm{mM}$

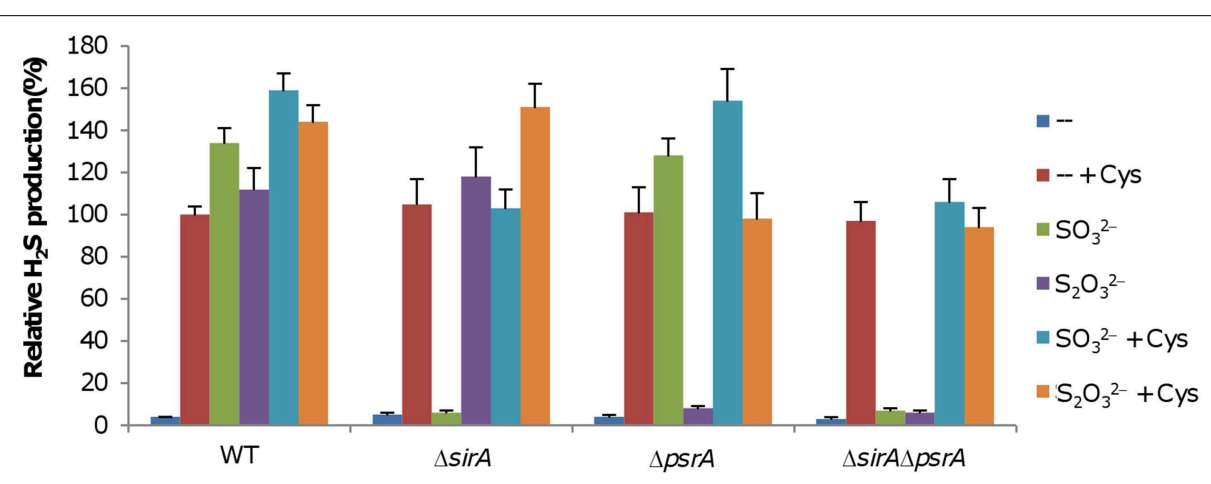

FIGURE 3 | Characteristics of $\mathrm{H}_{\mathbf{2}} \mathbf{S}$ generation by $\mathrm{S}$. oneidensis strains under anaerobic conditions. Fumarate of $5 \mathrm{mM}$ was used as EA to support growth to $\sim 0.2$ of $\mathrm{OD}_{600}$, which was then added with either $\mathrm{SO}_{3}^{2-}$ or $\mathrm{S}_{2} \mathrm{O}_{3}^{2-} \cdot \mathrm{H}_{2} \mathrm{~S}$ generation was measured $8 \mathrm{~h}$ after the addition. Averaged
$\mathrm{H}_{2} \mathrm{~S}$ level of the wild-type in the presence of cysteine was set to $100 \%$ for subsequent normalization as stated in Figure 2. "EA + Cys" represents the indicated EA plus cysteine. Data are presented as the mean $\pm \mathrm{SD}$ from at least four independent experiments. 


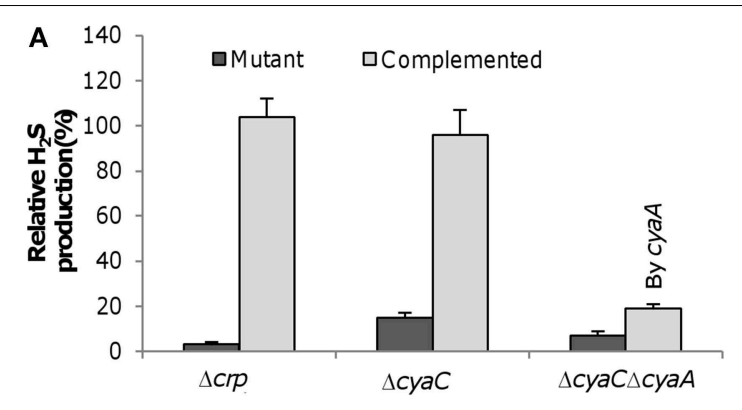

FIGURE 4 | Crp-cAMP is essential to $\mathrm{H}_{2} \mathrm{~S}$ generation by $\mathrm{S}$. oneidensis. (A) $\mathrm{H}_{2} \mathrm{~S}$ levels in anaerobic cultures of indicated mutants with $\mathrm{SO}_{3}^{2-}$ and $\mathrm{S}_{2} \mathrm{O}_{3}^{2-}$ at $2 \mathrm{mM}$ each were measured and normalized to values of the wild-type. TMAO of $5 \mathrm{mM}$ was used as EA to support growth to $\sim 0.2$ of $\mathrm{OD}_{600}$, which was then added with $\mathrm{SO}_{3}^{2-}$

cysteine under anaerobic conditions (Figure S5). The observed phenotypes resulting from the $\operatorname{crp}$ or $c y a C$ deletions were corrected by their expression in trans, confirming that the defect in $\mathrm{H}_{2} \mathrm{~S}$ synthesis was due to the intended mutations (Figure 4).

\section{Crp Directly Controls Transcription of psrA and sirA but Not mdeA, SO_1095, or sseA}

Given that Crp is the master regulator for anaerobic respiration and directly controls transcription of many genes encoding terminal reductases and their immediate regulators (Saffarini et al., 2003; Dong et al., 2012; Zhou et al., 2013), we predicted a similar scenario for the sirACD and $\operatorname{ps} A B C$ genes, or at least some of them. The $p s r A B C$ genes are predicted to be cotranscribed but the sirA and $\operatorname{sir} C D$ genes belong to two separate operons. To test whether these operons are under control of Crp, the promoters for these operons were predicted and fragments covering the promoter sequences were generated and placed in the front of the E. coli lacZ gene within pHGEI01 for $\beta$ galactosidase assay. In the $\Delta c r p$ strain, $\mathrm{P}_{s i r A}$ and $\mathrm{P}_{p s r A}$ were not responsive to $\mathrm{SO}_{3}^{2-}$ and $\mathrm{S}_{2} \mathrm{O}_{3}^{2-}$, respectively (Figure 5). However, the loss of Crp did not significantly affect the activity of $\mathrm{P}_{s i r C D}$. We then assessed the impact of the crp deletion on expression of the mdeA, SO_1095, and sseA genes. Surprisingly, none of these genes was negatively affected by the loss of Crp with respective to expression, even in the presence of cysteine (Figure 5).

In a previous study, operons under direct control of Crp were predicted by screening the $S$. oneidensis genome to identify those with conserved Crp-binding motifs in their upstream region (Gao et al., 2010b). The presence of such motifs in front of both the sirA and $p s r A B C$ operons is in line with our expression data presented above. To confirm there is direct interaction between Crp and the upstream region of the sir $A$ and $p s r A B C$ operons, we performed bacterial one-hybrid $(\mathrm{B} 1 \mathrm{H})$ analysis. The $\mathrm{B} 1 \mathrm{H}$ assay, a robust technique applicable to a wide variety of different transcriptional factor families, used here is derived from the BacterioMatch II two-hybrid system (Guo et al., 2009). To detect interaction, vectors containing "bait" (DNA) and "target" (DNA-binding regulator) are co-transformed into BacterioMatch II Validation Reporter Competent Cells, of which those having

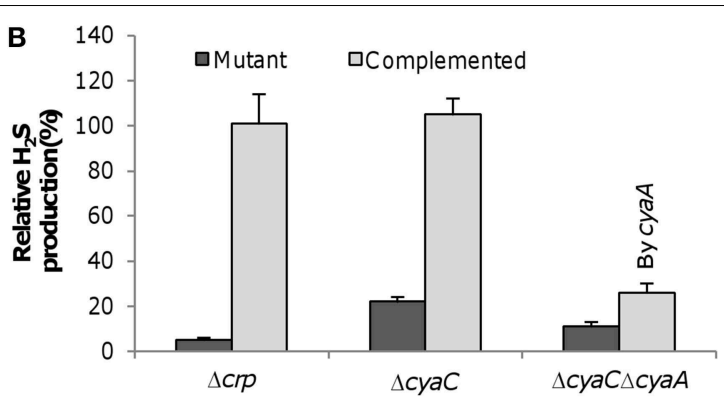

and $\mathrm{S}_{2} \mathrm{O}_{3}^{2-}$. (B) $\mathrm{H}_{2} \mathrm{~S}$ levels in aerobic cultures of indicated mutants with cysteine at $2 \mathrm{mM}$ were measured and normalized to values from the wild-type. In both $(\mathbf{A}, \mathbf{B})$ The double mutant $(\Delta c y a C \Delta c y a A)$ was complemented by the cyaA gene. Data are presented as the mean \pm $\mathrm{SD}$ from at least five independent experiments.

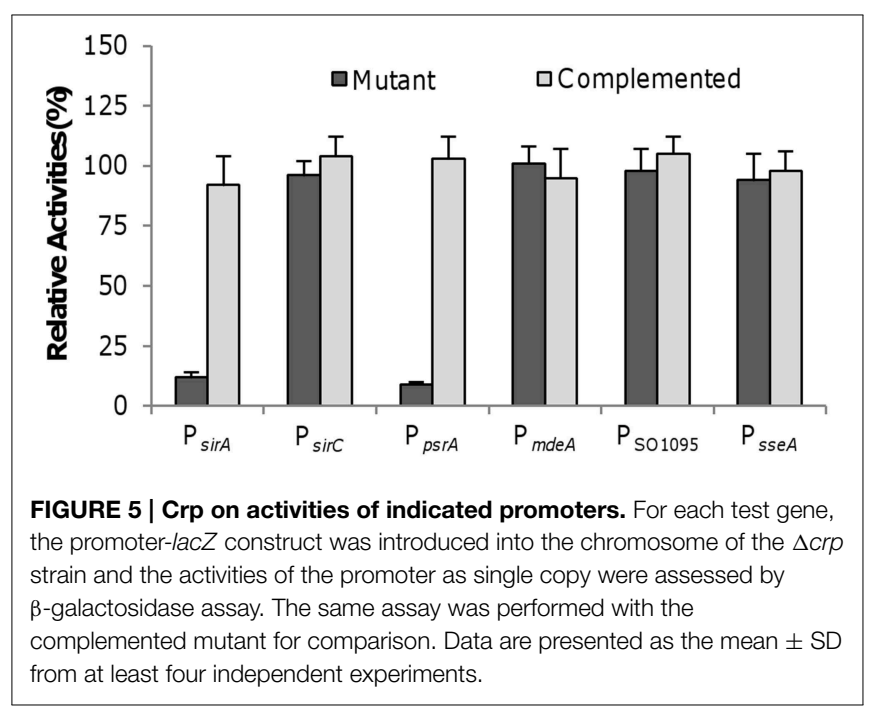

positive DNA-protein interactions are able to grow on 3-amino1,2,4-triazole (3-AT). To prepare the bait, a $\sim 300$ bp fragment centered by the predicted Crp-binding motif for each test gene was cloned into $\mathrm{pBXcmT}$, which was paired with $\mathrm{pTRG}$ carrying the $c r p$ gene for co-transformation. Positive interactions from $\mathrm{P}_{s i r A} /$ Crp and $\mathrm{P}_{p s r A} /$ Crp were detected and confirmed by growth on plates containing both 3 -AT and streptomycin $(12.5 \mathrm{mg}$ $\mathrm{ml}^{-1}$ ), contrasting all other test genes that failed to produce any colonies in $40 \mathrm{~h}$ on the selective or confirmation plates (Table 2). In summary, these data manifest that Crp, likely in a direct manner, activates transcription of the $\operatorname{sir} A$ and $p s r A B C$ operons but has little impact on the genes involved in cysteine degradation.

\section{ArcA Directly Represses Transcription of the mdeA Gene}

In S. oneidensis, the function of major global regulators, Crp, Arc, and Fnr, is substantially altered compared to their respective E. coli counterparts (Gao et al., 2010b). In E. coli, Fnr and Arc two-component system (TCS) are primarily responsible for 
TABLE 2 | Bacterial one-hybrid (B1H) assay of Crp with various promoters.

\begin{tabular}{llcccc}
\hline DNA & Regulator & $\begin{array}{c}\text { Colonies on } \\
\text { nonselective } \\
\text { plates }^{\text {a }}\end{array}$ & $\begin{array}{c}\text { Colonies on Confirmation } \\
\text { selective } \\
\text { plates }^{\text {b }}\end{array}$ & Interaction \\
\hline$/-$ & $/-$ & 197 & 0 & - & No \\
$/-$ & $/$ Crp & 163 & 0 & - & No \\
$/ P_{\text {cyd }}$ & $/-$ & 179 & 0 & - & No \\
$/ P_{\text {cyd }}$ & $/$ Crp & 174 & 169 & 168 & Yes \\
$/ P_{16 S}$ & $/$ Crp & 202 & 1 & 0 & No \\
$/ P_{\text {sirA }}$ & $/$ Crp & 183 & 168 & 155 & Yes \\
$/ P_{\text {sirC }}$ & $/$ Crp & 212 & 2 & 0 & No \\
$/ P_{\text {phs }}$ & $/$ Crp & 149 & 143 & 139 & Yes \\
$/ P_{\text {mdeA }}$ & $/$ Crp & 192 & 1 & 0 & No \\
$/ P_{\text {SO_1095 }} /$ Crp & 205 & 0 & - & No \\
$/ P_{\text {sseA }}$ & $/$ Crp & 183 & 3 & 0 & No \\
\hline
\end{tabular}

${ }^{a}$ M9 agar $+25 \mu \mathrm{g} / \mathrm{ml}$ chloramphenicol $+12.5 \mu \mathrm{g} / \mathrm{ml}$ tetracycline.

$b_{a}+5 m M 3-A T$.

${ }^{c} b+12.5 \mu \mathrm{g} / \mathrm{ml}$ streptomycin.

the switch between aerobic and anaerobic metabolism and Crp is the decisive regulator in the process of carbon repression (Green and Paget, 2004; Deutscher et al., 2006). Interestingly, the $S$. oneidensis counterpart of $E$. coli Fnr has no significant role in these processes and Arc appears to be important in aerobic respiration and plays a limited role in anaerobiosis (Gralnick et al., 2005; Gao et al., 2008, 2010b), whereas Crp becomes the most important regulator mediating aerobic and anaerobic respiration (Saffarini et al., 2003; Dong et al., 2012; Zhou et al., 2013). Given the functional switches among these regulators, we intended to examine whether Fnr or Arc influences $\mathrm{H}_{2} \mathrm{~S}$ synthesis in $\mathrm{S}$. oneidensis. Under aerobic and anaerobic conditions, loss of Fnr did not show any noticeable effect on $\mathrm{H}_{2} \mathrm{~S}$ generation, consistent with its overall dispensable role in respiration (Figure 6A). However, Arc, although negligible for $\mathrm{H}_{2} \mathrm{~S}$ generation from anaerobic respiration, apparently was involved in regulation of cysteine degradation. In line with that Arc functions as a repressor in general, the loss of the system resulted in overproduction of $\mathrm{H}_{2} \mathrm{~S}$ (Figure 6A).

To determine which genes are under influence of Arc, we measured the activity of promoters for all genes involved in $\mathrm{H}_{2} \mathrm{~S}$ generation (Figure 6B). Compared to the wild-type, the strain missing the fnr gene was indistinguishable in expression of all test genes, supporting that Fnr has no role in regulation of $\mathrm{H}_{2} \mathrm{~S}$ generation. In the case of Arc, although expression levels of the sirA, sirCD, psrABC, SO_1095, and sseA operons were barely altered in the $\operatorname{arc} A$ deletion strain, the $m d e A$ gene was expressed significantly higher compared to the wild-type. This repression by Arc is probably a result of direct binding to the upstream region of the operon because it contains an ArcA-binding motif (Gao et al., 2008; Wang et al., 2008). Moreover, we assessed the impact of Arc on expression of the cysK gene as its loss leads to a $\mathrm{H}_{2} \mathrm{~S}$ overproduction phenotype, similar to that resulting from the loss of ArcA. However, expression levels of the cysK gene were comparable between the $\operatorname{arcA}$ positive and negative strains (Figure 6B), eliminating a possibility that Arc plays a role in cysteine biosynthesis. These results conclude that Crp is essential for $\mathrm{H}_{2} \mathrm{~S}$ generation and Arc specifically regulates transcription of the $m d e A$ gene whereas Fnr is dispensable in S. oneidensis.

\section{Discussion}

The purpose of this study was to identify predominant sources of $\mathrm{H}_{2} \mathrm{~S}$ inside $\mathrm{S}$. oneidensis. Previous studies on anaerobic respiration of sulfur-containing substances had demonstrated that PsrABC and SirACD enzyme complexes could catalyze $\mathrm{H}_{2} \mathrm{~S}$ generation, provided that the corresponding EA was present (Burns and DiChristina, 2009; Shirodkar et al., 2011). PsrC and SirD belong to the NrfD/PsrC family of integral membrane proteins, which exclusively function as menaquinone oxidase/reductase (Simon and Kern, 2008). We provided evidence that these two complexes are predominantly, if not exclusively, accountable for $\mathrm{H}_{2} \mathrm{~S}$ generation via respiration of sulfur species. Interestingly, there is no interplay between the complexes detected in this study, indicating that they do not release intermediates for each other during respiration.

In parallel, the genome of $S$. oneidensis encodes many homologs of enzymes in cysteine degradation, whose counterparts are accountable for $\mathrm{H}_{2} \mathrm{~S}$ generation in mammals (Wang, 2012; Shatalin et al., 2011). By a combination of chemical and biological analyses, we determined that the predominant route for $\mathrm{H}_{2} \mathrm{~S}$ generation is through the MdeAbased cysteine degradation. As a methionine $\gamma$-lyase, MdeA is highly homologous to $P$. aeruginosa CSE, able to use L-cysteine as a substrate, together with $\mathrm{H}_{2} \mathrm{O}$, to produce pyruvate, $\mathrm{NH}_{3}$, and $\mathrm{H}_{2} \mathrm{~S}$ (Sato and Nozaki, 2009). Additionally, we found that another CSE homolog and a 3MST homolog, SO_1095 and SseA respectively, contributed to $\mathrm{H}_{2} \mathrm{~S}$ generation in $S$. oneidensis. Under aerobic growth conditions, MdeA accounts for at least two-thirds of $\mathrm{H}_{2} \mathrm{~S}$ that is generated endogenously, regardless of the presence of cysteine. SO_1095, which is surprisingly not subjected to cysteine induction, catalyzes the reaction that releases $\mathrm{H}_{2} \mathrm{~S}$ of $\sim 20 \%$ in the absence of additional cysteine. On the contrary, SseA is highly inducible by cysteine but without the inducer its contribution is negligible. S. oneidensis probably does not possess functional CBS as CBS homologs appear to be cysteine synthases, suggesting that the bacterium, similar to those studied before such as E. coli, lacks at least one of enzymes for $\mathrm{H}_{2} \mathrm{~S}$ generation via cysteine degradation (Shatalin et al., 2011).

In E. coli, the transcriptional regulator Fnr and the Arc TCS together control switches between aerobic and anaerobic respiration whereas Crp dictates carbon metabolism (Green and Paget, 2004; Deutscher et al., 2006). While Fnr of S. oneidensis has been reported to have a limited role in respiration of certain EAs (Maier and Myers, 2001; Cruz-Garcia et al., 2011), the data documented here, together with those presented previously, support the notion that the physiological significance of the regulator is marginal (Gao et al., 2010b; Fu et al., 2013; Zhou et al., 2013). The S. oneidensis Arc system is atypical, consisting of three components, ArcS, HptA and ArcA (Gralnick et al., 2005; Lassak et al., 2010; Shroff et al., 2010). Moreover, the regulons of the E. coli and S. oneidensis Arc systems have few components in common, suggesting a major difference in their physiological 


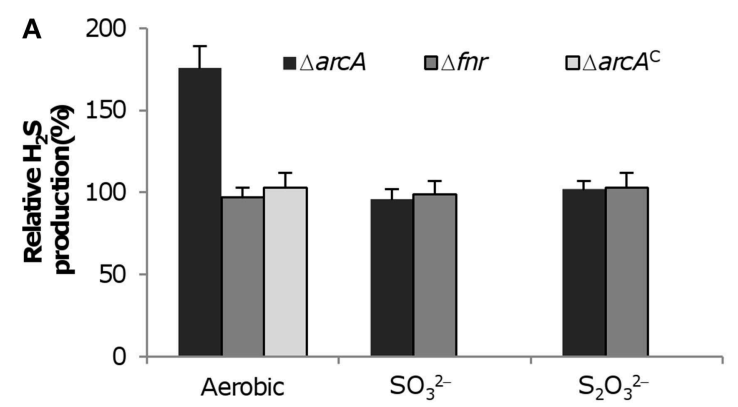

FIGURE 6 | Impact of loss of on $\mathrm{H}_{2} \mathrm{~S}$ generation in S. oneidensis. (A) ArcA and Fnr on $\mathrm{H}_{2} \mathrm{~S}$ generation. $\mathrm{H}_{2} \mathrm{~S}$ levels in cultures of indicated mutants grown aerobically or anaerobically with $10 \mathrm{mM} \mathrm{SO}_{3}^{2-}$ or $\mathrm{S}_{2} \mathrm{O}_{3}^{2-}$ as the sole EA were measured and normalized to values from the wild-type.

Complementation of the $\triangle \operatorname{arc} A$ mutant $\left(\Delta \operatorname{arc} A^{C}\right)$ was conducted with

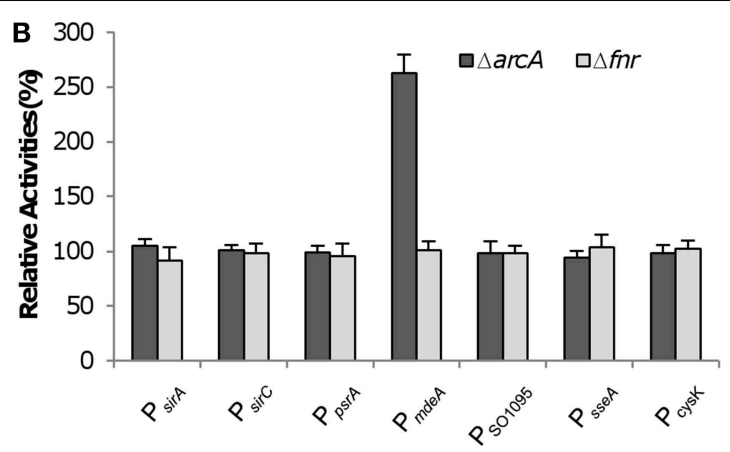

aerobic growth. (B) ArcA and Fnr on activities of indicated promoters. For each test gene, the promoter-lac $Z$ construct was introduced into the chromosome of the $\Delta c r p$ strain and the activities of the promoter as single copy were assessed by $\beta$-galactosidase assay. Data are presented as the mean \pm SD from at least four independent experiments. roles (Gao et al., 2008; Wang et al., 2008; Yuan et al., 2012). Several lines of evidence manifest that this three-component system functions primarily under aerobic conditions although it is required for dimethyl sulfoxide respiration, a phenomenon presumably arising from adventitious appearance of an ArcAbinding motif in front of the operon (Gao et al., 2008; Wang et al., 2008; Dong et al., 2014).

Instead, S. oneidensis employs Crp to control expression of most of respiratory reductases and, in some cases, their immediate regulators (Saffarini et al., 2003; Dong et al., 2012). Therefore, it is conceivable that expression of the psrA and sirA operons is mediated by Crp. By B1H analysis, we detected positive interactions between Crp and the upstream sequences of these two operons, manifesting that the regulation is carried out by Crp directly. Notably, the regulator of S. oneidensis resembles its $E$. coli counterpart in cAMP-dependent activation despite the substantial difference in Crp regulons between these two organisms (Charania et al., 2009; Zhou et al., 2013). This gains further support from the finding that loss of CyaC, the major cAMP synthetase, results in a phenotype similar to that caused by the Crp removal as shown here and before (Charania et al., 2009).

One of the most striking findings in this study is that Crp is also absolutely essential for $\mathrm{H}_{2} \mathrm{~S}$ generation via cysteine degradation in S. oneidensis. We do not know yet the mechanism underlying this essentiality. Expression of the mdeA, SO_1095, and $s s e A$ genes is not affected by the Crp removal, indicating that Crp influences biological processes beyond these proteins. Given

\section{References}

Bertani, G. (2004). Lysogeny at mid-twentieth century: P1, P2, and other experimental systems. J. Bacteriol. 186, 595-600. doi: 10.1128/JB.186.3.595600.2004

Bradley, A. S., Leavitt, W. D., and Johnston, D. T. (2011). Revisiting the dissimilatory sulfate reduction pathway. Geobiology 9, 446-457. doi: 10.1111/j.1472-4669.2011.00292.x that the loss of Crp abolishes cysteine induction, we speculate that the regulator may play an essential role in controlling intracellular cysteine levels. Unlike Crp, the involvement of the Arc system in $\mathrm{H}_{2} \mathrm{~S}$ generation via cysteine degradation is clear. The TCS represses expression of the $m d e A$ gene likely in a direct control manner. To date, little is known about the environmental cues for S. oneidensis ArcS, but it is clearly different from the E. coli paradigm as the atypical system functions under both aerobic and anaerobic conditions (Gralnick et al., 2005; Gao et al., 2008; Yuan et al., 2012). We are working to decipher the mechanism by which Crp dictates $\mathrm{H}_{2} \mathrm{~S}$ generation via cysteine degradation and to identify the signal triggering the Arc system.

\section{Acknowledgments}

This research was supported by National Natural Science Foundation of China (31270097, 41476105), Major State Basic Research Development Program (973 Program: 2010CB833803), and Doctoral Fund of Ministry of Education of China (20130101110142).

\section{Supplementary Material}

The Supplementary Material for this article can be found online at: http://journal.frontiersin.org/article/10.3389/fmicb. 2015.00374/abstract 
Charania, M. A., Brockman, K. L., Zhang, Y., Banerjee, A., Pinchuk, G. E., Fredrickson, J. K., et al. (2009). Involvement of a membrane-bound class III adenylate cyclase in regulation of anaerobic respiration in Shewanella oneidensis MR-1. J. Bacteriol. 191, 4298-4306. doi: 10.1128/JB.01829-08

Cordova, C. D., Schicklberger, M. F., Yu, Y., and Spormann, A. M. (2011). Partial functional replacement of CymA by SirCD in Shewanella oneidensis MR-1. J. Bacteriol. 193, 2312-2321. doi: 10.1128/JB.01355-10

Cruz-Garcia, C., Murray, A. E., Rodrigues, J. L., Gralnick, J. A., McCue, L. A., Romine, M. F., et al. (2011). Fnr (EtrA) acts as a fine-tuning regulator of anaerobic metabolism in Shewanella oneidensis MR-1. BMC Microbiol. 11:64. doi: 10.1186/1471-2180-11-64

Das, S., Noe, J. C., Paik, S., and Kitten, T. (2005). An improved arbitrary primed PCR method for rapid characterization of transposon insertion sites. J. Microbiol. Methods 63, 89-94. doi: 10.1016/j.mimet.2005.02.011

Deutscher, J., Francke, C., and Postma, P. W. (2006). How phosphotransferase system-related protein phosphorylation regulates carbohydrate metabolism in bacteria. Microbiol. Mol. Biol. Rev. 70, 939-1031. doi: 10.1128/MMBR.00024-06

Dong, Y., Wan, F., Yin, J., and Gao, H. (2014). Ecological roles of Arc signal transduction system revealed by evolutionary genetic analysis. J. Bacteriol. Mycol. 1:8. Available online at: http://austinpublishinggroup.com/bacteriology/ fulltext/bacteriology-v1-id1007.php

Dong, Y., Wang, J., Fu, H., Zhou, G., Shi, M., and Gao, H. (2012). A Crp-dependent two-component system regulates nitrate and nitrite respiration in Shewanella oneidensis. PLoS ONE 7:e51643. doi: 10.1371/journal.pone.0051643

Flynn, T. M., O’Loughlin, E. J., Mishra, B., DiChristina, T. J., and Kemner, K. M. (2014). Sulfur-mediated electron shuttling during bacterial iron reduction. Science 344, 1039-1042. doi: 10.1126/science. 1252066

Fredrickson, J. K., Romine, M. F., Beliaev, A. S., Auchtung, J. M., Driscoll, M. E., Gardner, T. S., et al. (2008). Towards environmental systems biology of Shewanella. Nat. Rev. Micro. 6, 592-603. doi: 10.1038/nrmicro1947

Fu, H., Chen, H., Wang, J., Zhou, G., Zhang, H., Zhang, L., et al. (2013). Crpdependent cytochrome $b d$ oxidase confers nitrite resistance to Shewanella oneidensis. Environ. Microbiol. 15, 2198-2212. doi: 10.1111/1462-2920.12091

Fu, H., Jin, M., Ju, L., Mao, Y., and Gao, H. (2014). Evidence for function overlapping of CymA and the cytochrome $b c_{1}$ complex in the Shewanella oneidensis nitrate and nitrite respiration. Environ. Microbiol. 16, 3181-3195. doi: 10.1111/1462-2920.12457

Gao, H., Barua, S., Liang, Y., Wu, L., Dong, Y., Reed, S., et al. (2010a). Impacts of Shewanella oneidensis c-ype cytochromes on aerobic and anaerobic respiration. Microb. Biotechnol. 3, 455-466. doi: 10.1111/j.1751-7915.2010.00181.x

Gao, H., Wang, X., Yang, Z. K., Chen, J., Liang, Y., Chen, H., et al. (2010b). Physiological roles of ArcA, Crp, and EtrA and their interactive control on aerobic and anaerobic respiration in Shewanella oneidensis. PLoS ONE 5:e15295. doi: 10.1371/journal.pone.0015295

Gao, H., Wang, X., Yang, Z., Palzkill, T., and Zhou, J. (2008). Probing regulon of ArcA in Shewanella oneidensis MR-1 by integrated genomic analyses. BMC Genomics 9:42. doi: 10.1186/1471-2164-9-42

Gralnick, J. A., Brown, C. T., and Newman, D. K. (2005). Anaerobic regulation by an atypical Arc system in Shewanella oneidensis. Mol. Microbiol. 56, 1347-1357. doi: 10.1111/j.1365-2958.2005.04628.x

Green, J., and Paget, M. S. (2004). Bacterial redox sensors. Nat. Rev. Micro. 2, 954-966. doi: 10.1038/nrmicro1022

Guo, M., Feng, H., Zhang, J., Wang, W., Wang, Y., Li, Y., et al. (2009). Dissecting transcription regulatory pathways through a new bacterial one-hybrid reporter system. Genome Res. 19, 1301-1308. doi: 10.1101/gr.086595.108

Heinzinger, N. K., Fujimoto, S. Y., Clark, M. A., Moreno, M. S., and Barrett, E. L. (1995). Sequence analysis of the phs operon in Salmonella typhimurium and the contribution of thiosulfate reduction to anaerobic energy metabolism. J. Bacteriol. 177, 2813-2820.

Janda, J. M., and Abbott, S. L. (2014). The genus Shewanella: from the briny depths below to human pathogen. Crit. Rev. Microbiol. 40, 293-312. doi: 10.3109/1040841X.2012.726209

Jiang, Y., Dong, Y., Luo, Q., Li, N., Wu, G., and Gao, H. (2014). Protection from oxidative stress relies mainly on derepression of OxyR-dependent KatB and Dps in Shewanella oneidensis. J. Bacteriol. 196, 445-458. doi: 10.1128/JB.01077-13

Jin, M., Jiang, Y., Sun, L., Yin, J., Fu, H., Wu, G., et al. (2013). Unique organizational and functional features of the cytochrome $c$ maturation system in Shewanella oneidensis. PLoS ONE 8:e75610. doi: 10.1371/journal.pone.0075610
Jormakka, M., Yokoyama, K., Yano, T., Tamakoshi, M., Akimoto, S., Shimamura, T., et al. (2008). Molecular mechanism of energy conservation in polysulfide respiration. Nat. Struct. Mol. Biol. 15, 730-737. doi: 10.1038/nsmb.1434

Keseler, I. M., Mackie, A., Peralta-Gil, M., Santos-Zavaleta, A., Gama-Castro, S., Bonavides-Martínez, C., et al. (2013). EcoCyc: fusing model organism databases with systems biology. Nucleic Acids Res. 41, D605-D612. doi: 10.1093/nar/gks1027

Kimura, H. (2014). Generation and physiological effects of hydrogen sulfide. Antioxid. Redox Signal. 20, 783-793. doi: 10.1089/ars.2013.5309

Lassak, J., Henche, A.-L., Binnenkade, L., and Thormann, K. M. (2010). ArcS, the cognate sensor kinase in an atypical Arc system of Shewanella oneidensis MR-1. Appl. Environ. Microbiol. 76, 3263-3274. doi: 10.1128/AEM.00512-10

Li, N., Luo, Q., Jiang, Y., Wu, G., and Gao, H. (2014). Managing oxidative stresses in Shewanella oneidensis: intertwined roles of the OxyR and OhrR regulons. Environ. Microbiol. 16, 1821-1834. doi: 10.1111/1462-2920.12418

Lohmayer, R., Kappler, A., Lösekann-Behrens, T., and Planer-Friedrich, B. (2014). Sulfur species as redox partners and electron shuttles for ferrihydrite reduction by Sulfurospirillum deleyianum. Appl. Environ. Microbiol. 80, 3141-3149. doi: 10.1128/AEM.04220-13

Maier, T. M., and Myers, C. R. (2001). Isolation and characterization of a Shewanella putrefaciens MR-1 electron transport regulator etrA mutant: reassessment of the role of EtrA. J. Bacteriol. 183, 4918-4926. doi: 10.1128/JB.183.16.4918-4926.2001

Myers, C. R., and Nealson, K. H. (1988). Bacterial manganese reduction and growth with manganese oxide as the sole electron acceptor. Science 240, 1319-1321. doi: $10.1126 /$ science.240.4857.1319

Oliveira, T. F., Vonrhein, C., Matias, P. M., Venceslau, S. S., Pereira, I. A., and Archer, M. (2008). The crystal structure of Desulfovibrio vulgaris dissimilatory sulfite reductase bound to DsrC provides novel insights into the mechanism of sulfate respiration. J. Biol. Chem. 283, 34141-34149. doi: $10.1074 /$ jbc.M805643200

Reese, M. G. (2001). Application of a time-delay neural network to promoter annotation in the Drosophila melanogaster genome. Comput. Chem. 26, 51-56. doi: 10.1016/S0097-8485(01)00099-7

Saffarini, D. A., Schultz, R., and Beliaev, A. (2003). Involvement of cyclic AMP (cAMP) and cAMP receptor protein in anaerobic respiration of Shewanella oneidensis. J. Bacteriol. 185, 3668-3671. doi: 10.1128/JB.185.12.3668-367 1.2003

Sato, D., and Nozaki, T. (2009). Methionine gamma-lyase: the unique reaction mechanism, physiological roles, and therapeutic applications against infectious diseases and cancers. IUBMB Life 61, 1019-1028. doi: 10.1002/iub.255

Shatalin, K., Shatalina, E., Mironov, A., and Nudler, E. (2011). $\mathrm{H}_{2} \mathrm{~S}$ : a universal defense against antibiotics in bacteria. Science 334, 986-990. doi: 10.1126/science. 1209855

Shirodkar, S., Reed, S., Romine, M., and Saffarini, D. (2011). The octahaem SirA catalyses dissimilatory sulfite reduction in Shewanella oneidensis MR-1. Environ. Microbiol. 13, 108-115. doi: 10.1111/j.1462-2920.2010.02313.x

Shroff, N. P., Charania, M. A., and Saffarini, D. A. (2010). ArcB1, a homolog of Escherichia coli $\mathrm{ArcB}$, regulates dimethyl sulfoxide reduction in Shewanella oneidensis MR-1. J. Bacteriol. 192, 3227-3230. doi: 10.1128/JB.01695-09

Siegel, L. M. (1965). A direct microdetermination for sulfide. Anal. Biochem. 11, 126-132. doi: 10.1016/0003-2697(65)90051-5

Simon, J., and Kern, M. (2008). Quinone-reactive proteins devoid of haem b form widespread membrane-bound electron transport modules in bacterial respiration. Biochem. Soc. Trans. 36, 1011-1016. doi: 10.1042/BST0361011

Wang, R. (2012). Physiological implications of hydrogen sulfide: a whiff exploration that blossomed. Physiol. Rev. 92, 791-896. doi: 10.1152/physrev.00017.2011

Wang, X., Gao, H., Shen, Y., Weinstock, G. M., Zhou, J., and Palzkill, T. (2008). A high-throughput percentage-of-binding strategy to measure binding energies in DNA-protein interactions: application to genome-scale site discovery. Nucleic Acids Res. 36, 4863-4871. doi: 10.1093/nar/gkn477

Wu, L., Wang, J., Tang, P., Chen, H., and Gao, H. (2011). Genetic and molecular characterization of flagellar assembly in Shewanella oneidensis. PLoS ONE 6:e21479. doi: 10.1371/journal.pone.0021479

Yin, J., Jin, M., Zhang, H., Ju, L., Zhang, L., and Gao, H. (2015). Regulation of nitrite resistance of the cytochrome $c b b_{3}$ oxidase by cytochrome $c$ ScyA in Shewanella oneidensis. Microbiologyopen 4, 84-99. doi: 10.1002/mbo3.224 
Yuan, J., Wei, B., Lipton, M. S., and Gao, H. (2012). Impact of ArcA loss in Shewanella oneidensis revealed by comparative proteomics under aerobic and anaerobic conditions. Proteomics 12, 1957-1969. doi: 10.1002/pmic.2011 00651

Yuan, J., Wei, B., Shi, M., and Gao, H. (2011). Functional assessment of EnvZ/OmpR two-component system in Shewanella oneidensis. PLoS ONE 6:e23701. doi: 10.1371/journal.pone.0023701

Zhou, G., Yin, J., Chen, H., Hua, Y., Sun, L., and Gao, H. (2013). Combined effect of loss of the $\mathrm{Caa}_{3}$ oxidase and Crp regulation drives Shewanella to thrive in redox-stratified environments. ISME J. 7, 1752-1763. doi: 10.1038/ismej. 2013.62
Conflict of Interest Statement: The authors declare that the research was conducted in the absence of any commercial or financial relationships that could be construed as a potential conflict of interest.

Copyright (c) $2015 \mathrm{Wu}, \mathrm{Li}, \mathrm{Mao}$, Zhou and Gao. This is an open-access article distributed under the terms of the Creative Commons Attribution License (CC $B Y)$. The use, distribution or reproduction in other forums is permitted, provided the original author(s) or licensor are credited and that the original publication in this journal is cited, in accordance with accepted academic practice. No use, distribution or reproduction is permitted which does not comply with these terms. 